\title{
Safety and Efficacy of a Novel Treatment for Advanced Liver Fibrosis
}

\author{
Mohammed Ahmed Nagah \\ BSc of Pharmaceutical Sciences, MSA University, 6th of October City, Egypt \\ Email: mohammednagah70@gmail.com
}

How to cite this paper: Nagah, M.A. (2020) Safety and Efficacy of a Novel Treatment for Advanced Liver Fibrosis. Open Journal of Gastroenterology, 10, 72-87. https://doi.org/10.4236/ojgas.2020.104008

Received: March 10, 2020

Accepted: April 17, 2020

Published: April 20, 2020

Copyright $\odot 2020$ by author(s) and Scientific Research Publishing Inc. This work is licensed under the Creative Commons Attribution International License (CC BY 4.0).

http://creativecommons.org/licenses/by/4.0/

\begin{abstract}
Background: Liver fibrosis is the presence of excess collagen due to new fibers formation. It is classified as a component of many forms of liver disease and injury rather than a disease by itself. To-date, there is no effective treatment for liver fibrosis. The only known way for patients suffering from advanced liver fibrosis is liver transplantation. Aim: The study was conducted to prove safety of Regehep (DAH04) as a novel treatment for treatment of advanced liver fibrosis in both of healthy adult volunteers. In addition, effectiveness and tolerability of Regehep (DAH04) in patients with advanced liver fibrosis. Method: Fourteen adult volunteers were enrolled for part A and $\mathrm{B}$. Part A, twelve adult healthy volunteers were randomly assigned into four groups $(n=3)$ as section of safety. Part $B$, two patients were enrolled to asses tolerability and effectiveness of Regehep in case of advanced liver fibrosis. Single ascending dose was used to asses safety in part A while therapeutic dose was used to achieve primary and secondary end point in part B. Results: There were no serious side effects as well as no serious biochemical changes after administration of single ascending doses of Regehep (DAH04) up to 25 folds of therapeutic dose. While part B, two cases of advanced liver fibrosis showed improvement of biochemical profile and ultrasound images of the liver till curing of periportal fibrosis as secondary end point. Conclusion: Regehep (DAH04) appears to be safe in doses up to 25 folds of therapeutic dose as well as effective in treatment of periportal fibrosis in late stages.
\end{abstract}

\section{Keywords}

Advanced Liver Fibrosis, Regehep, Biochemical Profile, Ultrasound Images, Curing of Periportal Fibrosis

\section{Introduction}

Liver disease accounts for approximately 2 million deaths per year worldwide, 1 
million due to complications of cirrhosis and 1 million due to viral hepatitis and hepatocellular carcinoma (HCC) [1]. Liver fibrosis is one of the leading causes of mortality [2]-[9]. This is because it changes the architecture of certain organs and disrupts normal functions [2]-[9].

Liver fibrosis is a histological consequence of wound healing process resulting from chronic liver diseases by viral hepatitis, schistososma, non-alcoholic fatty liver, alcoholic fatty liver and toxins [10]. Progressive liver fibrosis is linked to architectural changes of liver with increased stiffness favoring portal hypertension [8]. It advances to end stage liver cirrhosis and provides micro-environment predisposing hepatocellular carcinoma [8]. Distribution of liver fibrous tissues depends on the origin of liver injury. In case of viral hepatitis, cholestasis and shcistosomasis, fibrous tissues are initially located around portal tract. While in case of alcohol-related liver disease, fibrous tissues located peri-centrally. Deposition of excess extracellular matrix that is rich in fibril-forming collagen is a typical finding of liver fibrosis [11]. Excess deposition of extracellular matrix changes the normal architecture of the liver resulting in pathophysiological damage of the organ.

Moreover, advanced stage of liver fibrosis is defined as liver cirrhosis. It is characterized by further distortion of hepatic architecture and vasculature. Histologically, regenerative nodules with fibrous tissues are formed in response to chronic liver injury [1] [10]-[14].

The mechanism of liver fibrosis is thought to be associated with liver damage by various etiological factors followed by activation of hepatic stellate cells (HSCs) within the liver that develop into myofibroblasts [12]. Main cells affected by chronic liver disease are hepatic stellate cells (HSCs) and fibroblasts, which are activated by soluble mediators produced by activated Kupffer's cells or inflammatory cells during liver injury [15]. Hepatic stellate cells (HSCs) cause changes in cell behavior, including proliferation, chemotaxis, fibrogenesis, contractility, matrix degradation and retinoid loss.

There are general lab findings that are frequently found in case of liver cirrhosis. AST and ALT often normal or moderately elevated. This is because their Leakage from damaged hepatocytes; AST to ALT ratio often above 1 [4] [5] [16]. Bilirubin elevated considered important predictor of mortality in cases cholestasis, decreased hepatocyte and renal excretory function [4] [5] [16]. Albumin Decreased in advanced cirrhosis. This is because of decreasing hepatic production, sequestration into ascites and interstitium [4] [5] [16]. Prothrombin time decreased in advanced cirrhosis. This is because of decreasing hepatic production of factor V/VII [4] [5] [16]. Anemia Macro-, normo- or microcytic anemia due to folate deficiency, hypersplenism, direct toxicity (alcohol) and gastrointestinal blood loss [4] [5] [16]. Thrombocytes and leukocytes due to hypersplenism, dysfibronogenemia, reduced hepatic thrombopoietin production that is known as thrombocytopenia [4] [5] [16]. On the other hand, ultrasonography technique provides images of hepatic architecture, echogenicity, nodularity, shape, out and 
lines portal area showed periportal fibrosis [2]-[6] [11] [12] [13] [14].

To-date, there is no effective treatment for advanced liver fibrosis. The only known way for treatment of patients suffering from advanced liver fibrosis is liver transplantation. The way to cure liver fibrosis is going to be achieved by finding an effective molecule able to inhibit hepatic stellate cells (HSCs), degrade formed extracellular matrix and regenerate damaged liver cells. Regehep (DAH04) is an innovative molecule proved its efficacy in preclinical phases in curing liver fibrosis and regenerate damaged liver cells in addition to restoring normal liver architecture. Not only preclinical phase but also it proved its efficacy and safety in clinical stage.

\section{Study Design}

Fourteen adult volunteers were enrolled for part A and B. Twelve healthy adult volunteers were randomly assigned into four groups $(n=3)$ for part A related to safety. While two patients with advanced liver fibrosis were enrolled for part B related to efficacy and tolerability of Regehep in treatment of advanced liver fibrosis.

\section{Inclusion criteria}

Part A:

Average age: 28 years;

Average weight: $82.25 \mathrm{~kg}$;

Average height: $175.66 \mathrm{~cm}$;

Gender: Male;

No metabolic disorders;

No history of chronic diseases;

No history of malignancy or family history of malignancy;

No history of alcohol abuse;

No history of mental or psychological disorders.

\section{Part B:}

Average Age: 53 years;

Average Weight: $93 \mathrm{~kg}$;

Average Height: $172 \mathrm{~cm}$;

Gender: Males;

Condition: Shrunken liver with periportal fibrosis, irregular boarders, coarse echogenicity;

Causative Agent: Virus \& Schistosoma;

Primary Endpoint: Enhance echogenicity, restore normal size and normal boarders \& enhance biochemical findings;

Secondary end point: Completely curing of periportal fibrosis.

\section{Exclusion criteria}

Part A:

Severity of biochemical parameters after each single dose.

Severity of side effects at each stage of doses ascending. 


\section{Part B:}

Severity of side effects.

Achievement of primary and secondary end point.

\section{Excluded groups:}

Group 4 was excluded after first dose due to severity of side effects.

\section{Protocol}

\section{Part A:}

Investigated doses of each group and dose escalation in part A was driven by assessment of safety profile.

Group 1: Three subjects were enrolled each one was administrated initial dose of $10 \%$ of the therapeutic dose orally.

Group 2: The dose was escalated. Three subjects were enrolled each one was administrated $50 \%$ of the therapeutic dose orally.

Group 3: The dose was escalated. Three subjects were enrolled each one was administrated 25 folds of the therapeutic dose orally.

Group 4: The dose was escalated. Three subjects were enrolled each one was administrated 50 folds of the therapeutic dose orally.

Investigation Technique and time of investigation: Biochemical analysis (Complete Blood Picture, Liver profile, Kidney profile \& Electrolytes balance) before administration of Regehep, 2.5 hours and 7.5 hours after administration of Regehep.

\section{Part B:}

Investigation Technique and time of investigation: Biochemical analysis (Complete Blood Picture, Liver profile, Kidney profile \& Coagulation profile) and Ultrasound Images of liver. For case 1, before administration, 3 weeks and 6 weeks after administration of Regehep. While for case 2 before administration, 6 weeks and 12 weeks after administration of Regehep.

Therapeutic doses were administrated twice/day.

Case 1 duration: 6 weeks.

Case 2 duration: 12 weeks.

\section{Results}

\section{Part A:}

Safety of Regehep was assayed by examination of biochemical markers (Vital signs, Blood count, Liver profile, Kidney profile \& Electrolytes balance) and severity of side effects that were scored after asking each individual healthy volunteers (Tables 1-5). Each individual healthy volunteer's samples were assayed at time guided by dose-escalating schedule.

All groups showed non-significant differences of vital signs (Blood pressure \& Blood glucose) values 2.5 hours and 7.5 hours after single ascending doses of Regehep $(\mathrm{P}>0.05)$ when compared to normal values before administration of single ascending doses up to 25 folds of therapeutic dose (Table 1 ). 
All groups showed non-significant differences of blood count values 2.5 hours and 7.5 hours after single ascending doses of Regehep $(\mathrm{P}>0.05)$ when compared to normal values before administration of single ascending doses up to 25 folds of therapeutic dose except White blood cells count (Table 2). White blood cells count showed significant elevation $(\mathrm{P}<0.001) 2.5$ hours and 7.5 hours after single ascending doses of Regehep up to 25 folds of therapeutic dose when compared to normal values before administration of single ascending doses (Table 2).

All groups showed non-significant differences of liver profile (ALT, AST, ALP, GGT \& Total protein) $(\mathrm{P}>0.05) 2.5$ hours and 7.5 hours after single ascending doses of Regehep $(\mathrm{P}>0.05)$ when compared to normal values before administration of single ascending doses up to 25 folds of therapeutic dose. While

Table 1. Showed vital signs of all included groups before administration of single ascending doses, 2.5 and 7.5 after administration of single ascending doses of Regehep. Data is presented as mean $\pm \mathrm{SD}$ of each group. Statistical analysis was carried out by one way analysis of variance (ANOVA) followed by Tukey-Kramer test for multiple comparisons.

\begin{tabular}{cccc}
\hline Test & Before Administration & $\begin{array}{c}2.5 \text { hrs. } \\
\text { after administration }\end{array}$ & $\begin{array}{c}7.5 \text { hrs. } \\
\text { after administration }\end{array}$ \\
\hline Blood Pressure & $117.11 / 76.88 \pm 4.512 / 6.585$ & $118.77 / 78.44 \pm 4.410 / 2.963$ & $114.33 / 77.77 \pm 4.717 / 6.180$ \\
Blood Glucose & $115.7777 \pm 7.345$ & $110.4444 \pm 6.984$ & $115.4444 \pm 6.729$ \\
\hline
\end{tabular}

${ }^{\mathrm{a}}$ Compared with normal values $\mathrm{P}>0.05 ;{ }^{\mathrm{ab}}$ Compared with normal normal value $\mathrm{P}>0.05$.

Table 2. Showed blood picture of all included groups before administration of single ascending doses, 2.5 and 7.5 after administration of single ascending doses of Regehep. Data are presented as mean \pm SD of each group. Statistical analysis was carried out by one way analysis of variance (ANOVA) followed by Tukey-Kramer test for multiple comparisons.

\begin{tabular}{cccc}
\hline Test & $\begin{array}{c}\text { Before } \\
\text { Administration }\end{array}$ & $\begin{array}{c}2.5 \text { hrs. } \\
\text { after administration }\end{array}$ & $\begin{array}{c}7.5 \text { hrs. } \\
\text { after administration }\end{array}$ \\
\hline Hemoglobin & $14.212 \pm 0.6187$ & $14.45 \pm 0.6970$ & $14.383 \pm 0.621$ \\
RBCs & $4.812 \pm 0.3995$ & $4.93 \pm 0.4692$ & $4.981 \pm 0.4748$ \\
Hematocrit & $42.266 \pm 3.273$ & $42.65 \pm 4.25$ & $42.761 \pm 4.254$ \\
MCV & $83.88 \pm 3.140$ & $83.88 \pm 3.140$ & $83.88 \pm 3.140$ \\
MCH & $28.88 \pm 1.45$ & $28.88 \pm 1.45$ & $28.88 \pm 1.45$ \\
MCHC & $33.44 \pm 1.424$ & $34.222 \pm 1.563$ & $34.222 \pm 1.563$ \\
RDW-CV & $12.80 \pm 0.7868$ & $13.294 \pm 1.129$ & $13.466 \pm 0.8471$ \\
Platelets & $160.144 \pm 14.291$ & $175.666 \pm 16.560$ & $177.222 \pm 16.277$ \\
MPV & $9.091 \pm 0.885$ & $9.022 \pm 0.8614$ & $8.666 \pm 0.798$ \\
PDW & $14.336 \pm 1.718$ & $13.622 \pm 1.582$ & $14.044 \pm 1.198$ \\
WBCs & $5.533 \pm 0.7681$ & $8.1666 \pm 1.225$ & $7.455 \pm 1.305$ \\
\hline
\end{tabular}

${ }^{\mathrm{a}}$ Compared with normal values $\mathrm{P}>0.05$; ${ }^{\text {ab }}$ Compared with normal normal value $\mathrm{P}>0.05$. The data is presented graphically in Figure 1. 


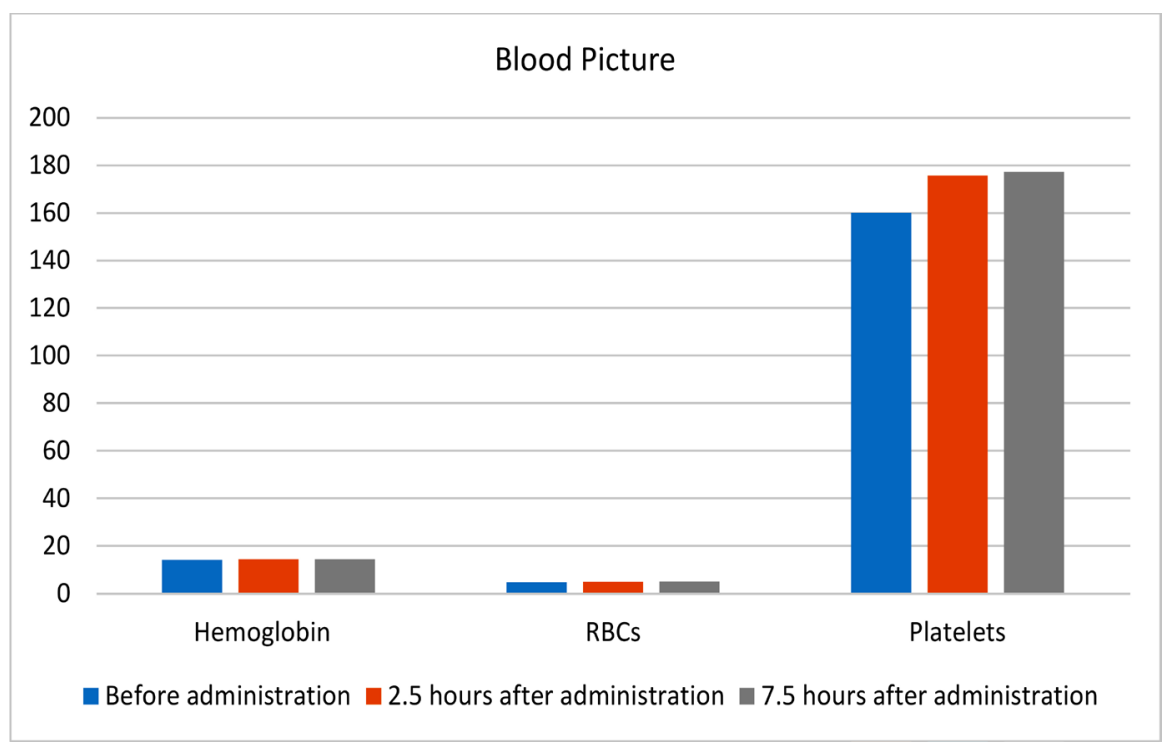

Figure 1. Showed comparison between main blood picture count of all included groups before administration of single ascending doses, 2.5 and 7.5 after administration of single ascending doses of Regehep. Data are presented as mean \pm SD of each group. Statistical analysis was carried out by one way analysis of variance (ANOVA) followed by Tukey-Kramer test for multiple comparisons.

Table 3. Showed liver profile of all included groups before administration of single ascending doses, 2.5 and 7.5 after administration of single ascending doses of Regehep. Data is presented as mean \pm SD of each group. Statistical analysis was carried out by one way analysis of variance (ANOVA) followed by Tukey-Kramer test for multiple comparisons.

\begin{tabular}{cccc}
\hline Test & Before Administration & $\begin{array}{c}2.5 \text { hrs. } \\
\text { after administration }\end{array}$ & $\begin{array}{c}\mathbf{7 . 5} \text { hrs. } \\
\text { after administration }\end{array}$ \\
\hline ALT & $33.273 \pm 5.055$ & $31.077 \pm 6.426$ & $34.83 \pm 4.742$ \\
AST & $27.361 \pm 3.817$ & $29.98 \pm 3.523$ & $23.554 \pm 3.516$ \\
ALP & $107.961 \pm 18.976$ & $118.23 \pm 15.218$ & $117.044 \pm 19.112$ \\
Albumin & $4.3188 \pm 0.3383$ & $4.664 \pm 0.3533$ & $4.775 \pm 0.2277$ \\
Total bilirubin & $0.8022 \pm 0.1127$ & $0.54 \pm 0.1304$ & $0.282 \pm 0.1146$ \\
GGT & $19.111 \pm 4.226$ & $18.333 \pm 3.317$ & $20.444 \pm 4.304$ \\
Total protein & $6.9511 \pm 0.7765$ & $7.2166 \pm 0.8078$ & $6.7722 \pm 0.6897$ \\
\hline
\end{tabular}

${ }^{\mathrm{a} C o m p a r e d ~ w i t h ~ n o r m a l ~ v a l u e s ~} \mathrm{P}>0.05^{\text {ab }}$ Compared with normal normal value $\mathrm{P}>0.05$. The data is presented graphically in Figure 2.

liver profile (Albumin) showed significant elevation 7.5 hours after single ascending doses of Regehep up to 25 folds of therapeutic dose $(\mathrm{P}<0.05)$ when compared to normal values before administration of single ascending doses. In addition, liver profile (Total bilirubin) showed significant elevation 2.5 hours and 7.5 hours after single ascending doses of Regehep up to 25 folds of therapeutic dose $(\mathrm{P}<0.001)$ when compared to normal values before administration of single ascending doses (Table 3 ).

Kidney profile (Creatinine) showed non-significant differences 2.5 hours and 


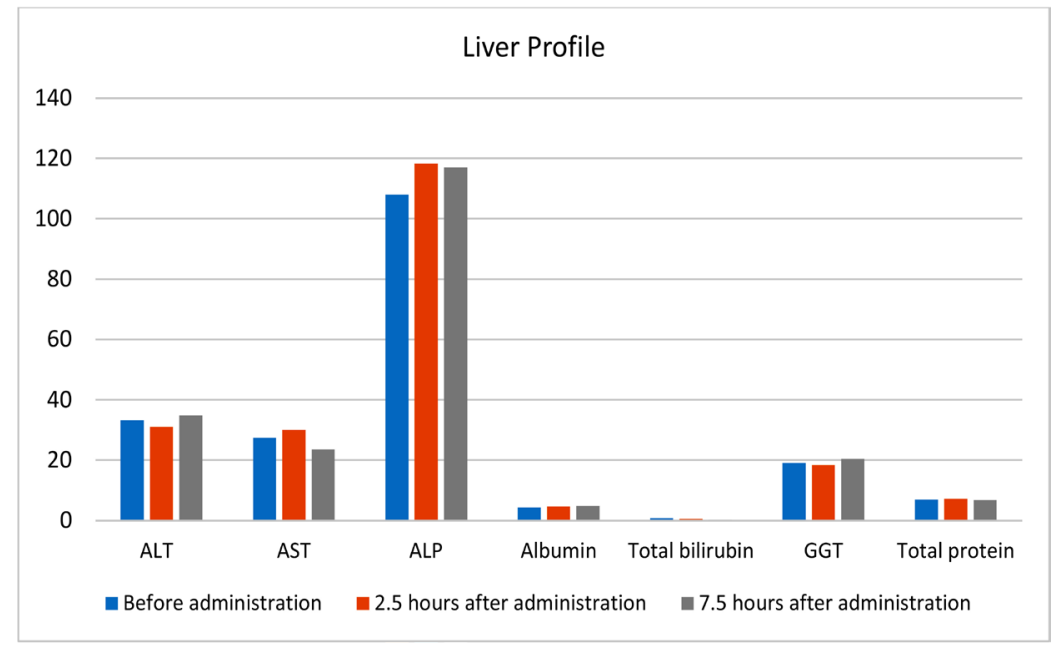

Figure 2. Showed comparison between liver profile of all included groups before administration of single ascending doses, 2.5 and 7.5 after administration of single ascending doses of Regehep. Data are presented as mean \pm SD of each group. Statistical analysis was carried out by one way analysis of variance (ANOVA) followed by Tukey-Kramer test for multiple comparisons.

Table 4. Showed kidney and electrolytes profile of all included groups before administration of single ascending doses, 2.5 and 7.5 after administration of single ascending doses of Regehep. Data are presented as mean \pm SD of each group. Statistical analysis was carried out by one way analysis of variance (ANOVA) followed by Tukey-Kramer test for multiple comparisons.

\begin{tabular}{cccc}
\hline Test & Before Administration & $\mathbf{2 . 5}$ hrs. after administration & 7.5 $^{\mathrm{a} r s . ~ a f t e r ~ a d m i n i s t r a t i o n}{ }^{\text {ab }}$ \\
\hline Creatinine & $0.7833 \pm 0.2181$ & $0.971 \pm 0.2104$ & $0.85 \pm 0.2182$ \\
Calcium & $8.8411 \pm 0.6074$ & $8.9333 \pm 0.6557$ & $8.5666 \pm 0.554$ \\
Sodium & $142.444 \pm 5.312$ & $143.355 \pm 4.841$ & $141.7044 \pm 5.716$ \\
Potassium & $4.4077 \pm 0.5420$ & $4.3116 \pm 0.4835$ & $4.0533 \pm 0.3919$ \\
\hline
\end{tabular}

${ }^{\mathrm{a}}$ Compared with normal values $\mathrm{P}>0.05^{\text {ab }}$ Compared with normal normal value $\mathrm{P}>0.05$. The data is presented graphically in Figure 3.

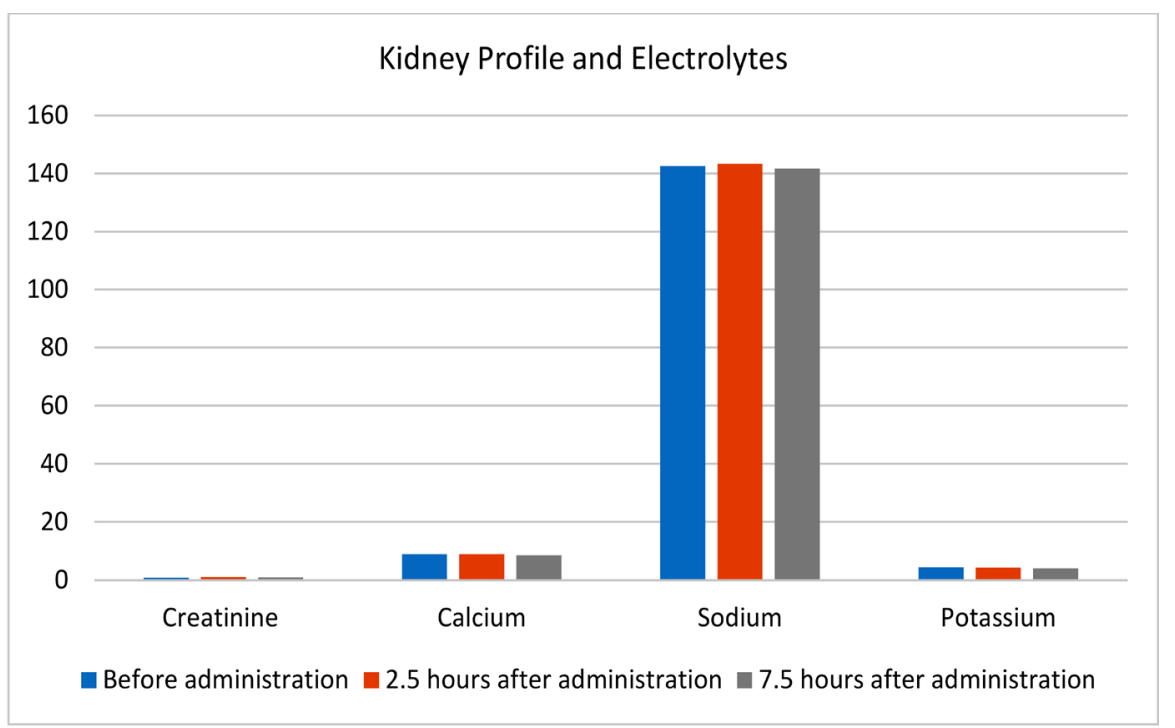

Figure 3. Showed comparison between kidney profile and electrolytes of all included groups before administration of single ascending doses, 2.5 and 7.5 after administration of single ascending doses of Regehep. Data are presented as mean \pm SD of each group. Statistical analysis was carried out by one way analysis of variance (ANOVA) followed by Tukey-Kramer test for multiple comparisons. 
Table 5. Side effects of Regehep when administrated in different doses in both healthy and patients with advanced liver fibrosis.

\begin{tabular}{|c|c|c|c|}
\hline Severity & Mild & Moderate & Severe \\
\hline Headache & + & ++ & +++ \\
\hline Heart Burn & + & ++ & +++ \\
\hline Dizziness & + & ++ & +++ \\
\hline GIT Disturbances & + & ++ & +++ \\
\hline Nausea & - & - & +++ \\
\hline Vomiting & - & - & +++ \\
\hline
\end{tabular}

7.5 hours after single ascending doses of Regehep $(\mathrm{P}>0.05)$ when compared to normal values before administration of single ascending doses up to 25 folds of therapeutic dose (Table 4).

Electrolytes (Calcium, Sodium \& Potassium) showed non-significant differences 2.5 hours and 7.5 hours after single ascending doses of Regehep $(P>0.05)$ when compared to normal values before administration of single ascending doses up to 25 folds of therapeutic dose (Table 4).

\section{Part B}

Efficacy of Regehep was assayed by examination of biochemical markers (Blood count, Liver profile, Kidney profile \& Coagulation profile) and ultrasound images of the liver (Tables 6-8). Moreover, each individual patient's sample and ultrasound images of the liver were assayed at definite interval time.

\section{Biochemical Analysis}

\section{Case 1}

Hemoglobin value showed significant decreasing after 3 and 6 weeks of treatment with Regehep $(\mathrm{P}<0.001)$ when compared to hemoglobin value before treatment. However, hemoglobin value showed significant elevation after 6 weeks of treatment with Regehep $(\mathrm{P}<0.001)$ when compared to hemoglobin value after 3 weeks of treatment (Table 6).

RBCs value showed significant decreasing after 6 weeks of treatment with Regehep $(\mathrm{P}<0.001)$ when compared to hemoglobin value before and 3 weeks after treatment. However, RBCs value showed non-significant differences after 3 weeks of treatment with Regehep $(\mathrm{P}>0.05)$ when compared to $\mathrm{RBCs}$ value before treatment (Table 6).

Platelet count showed significant elevation after 3 and 6 weeks of treatment with Regehep $(\mathrm{P}<0.001)$ when compared to platelet count before treatment. However, platelet count showed significant decreasing after 6 weeks of treatment with Regehep $(\mathrm{P}<0.001)$ when compared to platelet count after 3 weeks of treatment (Table 6).

ALT enzyme showed significant elevation after 3 and 6 weeks of treatment with Regehep $(P<0.001)$ when compared to ALT enzyme value before treat- 
ment. However, ALT enzyme showed non-significant differences after 6 weeks of treatment with Regehep ( $\mathrm{P}>0.05)$ when compared to ALT enzyme after 3 weeks of treatment (Table 7).

AST enzyme showed significant elevation after 6 weeks of treatment with Regehep $(\mathrm{P}<0.001)$ when compared to AST enzyme value before and 3 weeks after treatment (Table 7).

Albumin showed significant elevation after 3 and 6 weeks of treatment with Regehep $(\mathrm{P}<0.001)$ when compared to albumin value before treatment. However, it showed significant decreasing after 6 weeks of treatment with Regehep (P

Table 6. Showed the effect of Regehep in therapeutic dose on blood picture of patients with advanced liver fibrosis. The data are presented graphically in Figure 4.

\begin{tabular}{|c|c|c|c|c|c|c|c|c|}
\hline \multirow[b]{2}{*}{ Test } & \multicolumn{3}{|c|}{ Subject 1} & \multicolumn{3}{|c|}{ Subject 2} & \multirow[b]{2}{*}{ Unit } & \multirow[b]{2}{*}{ Ref. Range } \\
\hline & Before TTT & $\begin{array}{c}3 \text { weeks } \\
\text { after TTT }\end{array}$ & $\begin{array}{c}6 \text { weeks } \\
\text { after TTT }\end{array}$ & Before TTT & $\begin{array}{c}6 \text { weeks } \\
\text { after TTT }\end{array}$ & $\begin{array}{l}12 \text { weeks } \\
\text { after TTT }\end{array}$ & & \\
\hline Hemoglobin & 11.7 & 11.2 & 11.3 & 10.5 & 11.2 & 10.8 & $\mathrm{~g} / \mathrm{dl}$ & $13-18$ \\
\hline RBCs & 3.86 & 3.89 & 3.64 & 3.56 & 3.52 & 3.50 & $\times 10 / \mathrm{m}^{3}$ & $4.5-6$ \\
\hline Hematocrit & 36 & 36.6 & 34.2 & 34 & 32.2 & 31.8 & $\%$ & $41-50$ \\
\hline $\mathrm{MCV}$ & 93.3 & 94.2 & 94.2 & 95.7 & 91.5 & 91.1 & $\mathrm{fl}$ & $80-100$ \\
\hline $\mathrm{MCH}$ & 30.3 & 28.7 & 31 & 29.4 & 31.8 & 30.8 & pg & $27-32$ \\
\hline MCHC & 32.5 & 30.6 & 33 & 30.8 & 34.7 & 33.9 & $\mathrm{~g} / \mathrm{dl}$ & $32-36$ \\
\hline RDW-CV & 13.6 & 15.4 & 12.4 & 16.7 & 13.1 & 12 & $\%$ & $11.60-14$ \\
\hline Platelets & 32 & 120 & 43 & 33 & 36 & 48 & $\times 10 / \mathrm{m}^{3}$ & $150-450$ \\
\hline MPV & 9.3 & 8.8 & 9.3 & 7.8 & 9.1 & 8.8 & $\mathrm{fl}$ & $7.40-10.40$ \\
\hline PDW & 16.2 & 17.3 & 17 & 16.5 & 16.8 & 17.2 & $\mathrm{fl}$ & $9-14$ \\
\hline WBCs & 2.1 & 2.1 & 2.3 & 2.1 & 2.8 & 2.6 & $\times 10 / \mathrm{m}^{3}$ & $4.300-10.800$ \\
\hline
\end{tabular}

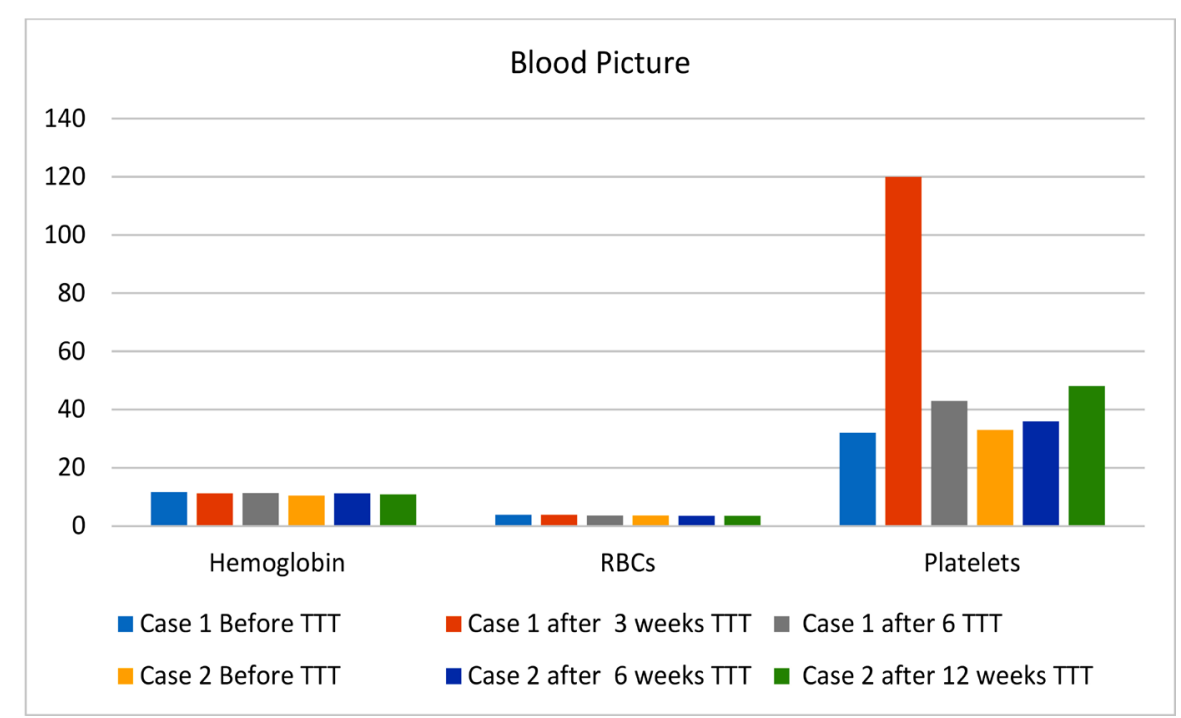

Figure 4. Showed comparison between effects of Regehep in therapeutic dose on blood picture of patients with advanced liver fibrosis before and after TTT. 
Table 7. Showed the effect of Regehep in therapeutic dose on liver and kidney profile of patients with advanced liver fibrosis. The data are presented graphically in Figure 5.

\begin{tabular}{|c|c|c|c|c|c|c|c|c|}
\hline \multirow[b]{2}{*}{ Test } & \multicolumn{3}{|c|}{ Subject 1} & \multicolumn{3}{|c|}{ Subject 2} & \multirow[b]{2}{*}{ Unit } & \multirow[b]{2}{*}{ Ref. Range } \\
\hline & Before TTT & $\begin{array}{c}3 \text { weeks } \\
\text { after TTT }\end{array}$ & $\begin{array}{c}6 \text { weeks } \\
\text { after TTT }\end{array}$ & Before TTT & $\begin{array}{c}6 \text { weeks } \\
\text { after TTT }\end{array}$ & $\begin{array}{l}12 \text { weeks } \\
\text { after TTT }\end{array}$ & & \\
\hline ALT & 23 & 34 & 35 & 18 & 32 & 29 & $\mathrm{U} / \mathrm{L}$ & Up to 45 \\
\hline AST & 47 & 53 & 83 & 51 & 38 & 41 & $\mathrm{U} / \mathrm{L}$ & Up to 40 \\
\hline Albumin & 3.1 & 3.4 & 3.3 & 3.2 & 3.1 & 3.3 & $\mathrm{~g} / \mathrm{dl}$ & $3.5-5.5$ \\
\hline Total bilirubin & 1.5 & 1.79 & 1.3 & 1.6 & 1.3 & 1.5 & $\mathrm{mg} / \mathrm{dl}$ & Up to 1.2 \\
\hline Direct bilirubin & 0.6 & 0.54 & 0.5 & 0.55 & 0.35 & 0.4 & $\mathrm{mg} / \mathrm{dl}$ & Up to 0.25 \\
\hline Indirect bilirubin & 0.9 & 1.25 & 0.8 & 1.05 & 0.95 & 1.05 & $\mathrm{mg} / \mathrm{dl}$ & Up to 1.0 \\
\hline Creatinine & 0.8 & 1.1 & 1.1 & 1.53 & 1.5 & 1.4 & $\mathrm{mg} / \mathrm{dl}$ & $6-8$ \\
\hline
\end{tabular}

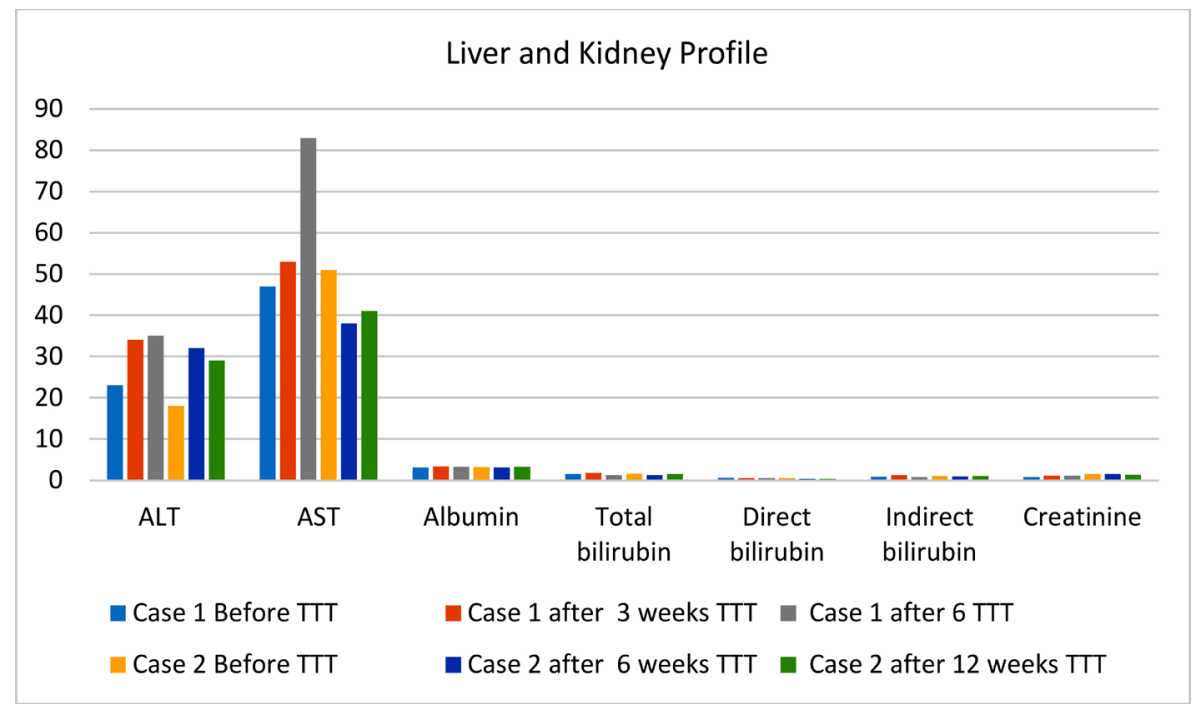

Figure 5. Showed comparison between effects of Regehep in therapeutic dose on liver and kidney profile of patients with advanced liver fibrosis before and after TTT.

Table 8. Showed the effect of Regehep in therapeutic dose on coagulation profile of patients with advanced liver fibrosis. The data are presented graphically in Figure 6.

\begin{tabular}{|c|c|c|c|c|c|c|c|c|}
\hline \multirow[b]{2}{*}{ Test } & \multicolumn{3}{|c|}{ Subject 1} & \multicolumn{3}{|c|}{ Subject 2} & \multirow[b]{2}{*}{ Unit } & \multirow[b]{2}{*}{ Ref. Range } \\
\hline & Before TTT & $\begin{array}{c}3 \text { weeks } \\
\text { after TTT }\end{array}$ & $\begin{array}{l}6 \text { weeks } \\
\text { after TTT }\end{array}$ & Before TTT & $\begin{array}{l}6 \text { weeks } \\
\text { after TTT }\end{array}$ & $\begin{array}{l}12 \text { weeks } \\
\text { after TTT }\end{array}$ & & \\
\hline Patient's time & 19.7 & 16.23 & 17.28 & 18.85 & 18.34 & 17.86 & Second & $11-13$ \\
\hline Control's time & 12.7 & 12.7 & 12.7 & 12.7 & 12.7 & 12.7 & Second & \\
\hline Concentration & 60 & 65 & 67 & 50 & 52.5 & 55 & $\%$ & $70 \%-100 \%$ \\
\hline I.N.R & 1.64 & 1.45 & 1.36 & 1.81 & 1.73 & 1.67 & & $1.0-1.3$ \\
\hline
\end{tabular}

$<0.01$ ) when compared to albumin value after 3 weeks of treatment (Table 7).

Total bilirubin showed significant elevation after 3 weeks of treatment with

Regehep $(\mathrm{P}<0.001)$ when compared to total bilirubin value before treatment. 


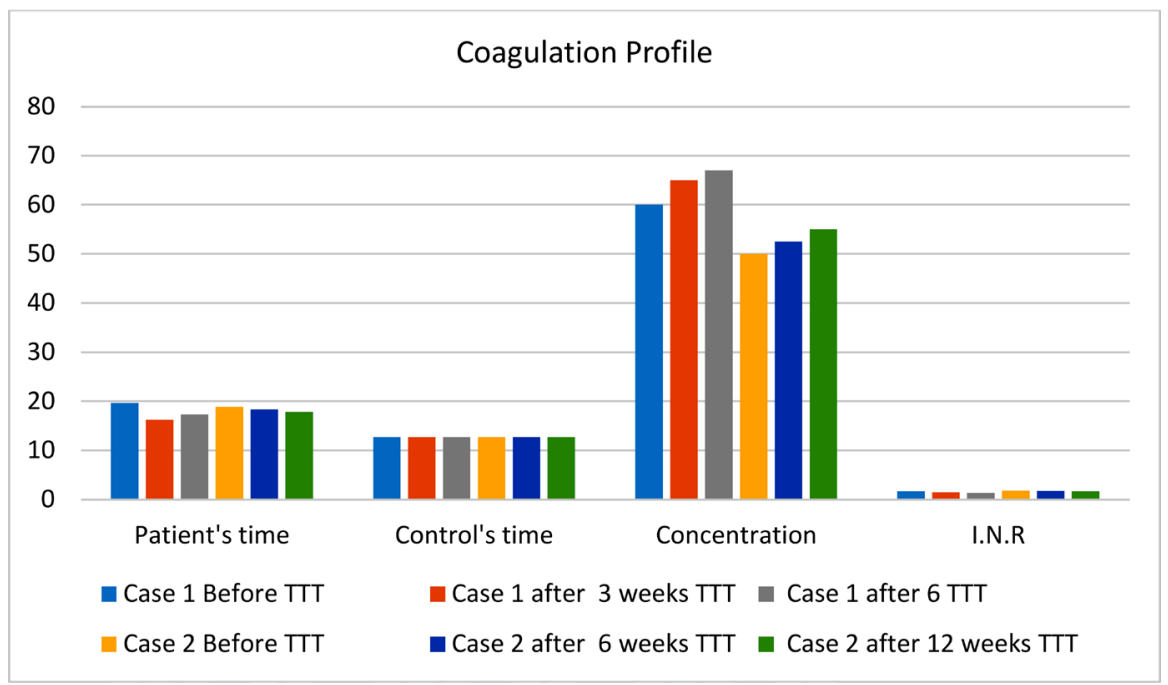

Figure 6. Showed comparison between effects of Regehep in therapeutic dose on coagulation profile of patients with advanced liver fibrosis before and after TTT.

While it showed significant decreasing after 6 weeks of treatment with Regehep $(\mathrm{P}<0.001)$ when compared to total bilirubin value before and 3 weeks after treatment (Table 7).

Direct bilirubin showed significant decreasing after 6 weeks of treatment with Regehep $(\mathrm{P}<0.01)$ when compared to direct bilirubin value before treatment. While it showed non-significant differences after 6 weeks of treatment with Regehep $(\mathrm{P}<0.05)$ when compared to direct bilirubin value before and 3 weeks after treatment (Table 7).

Indirect bilirubin showed significant decreasing after 6 weeks of treatment with Regehep $(\mathrm{P}<0.001)$ when compared to direct bilirubin value before and 3 weeks after treatment. While it showed significant increasing after 3 weeks of treatment with Regehep $(\mathrm{P}<0.001)$ when compared to direct bilirubin value before treatment (Table 7).

Creatinine showed significant elevation after 3 and 6 weeks of treatment with Regehep $(\mathrm{P}<0.001)$ when compared to creatinine value before treatment. However, it showed non-significant differences after 6 weeks of treatment with Regehep $(\mathrm{P}>0.05)$ when compared to creatinie value after 3 weeks of treatment (Table 7).

Coagulation time showed significant decreasing after 3 and 6 weeks of treatment with Regehep $(\mathrm{P}<0.001)$ when compared to time before treatment. However, it showed significant decreasing after 6 weeks of treatment with Regehep (P $<0.01$ ) when compared to time after 3 weeks of treatment (Table 8).

Sample concentration showed significant elevation after 3 and 6 weeks of treatment with Regehep $(\mathrm{P}<0.001)$ when compared to concentration before treatment (Table 8).

I.N.R. showed significant decreasing after 3 and 6 weeks of treatment with Regehep $(\mathrm{P}<0.001)$ when compared to concentration before treatment. However, it showed significant elevation after 6 weeks of treatment with Regehep ( $P$ 
$<0.01$ ) when compared to value after 3 weeks of treatment (Table 8).

\section{Case 2}

Hemoglobin value showed significant elevation after 6 and 12 weeks of treatment with Regehep $(\mathrm{P}<0.001)$ when compared to hemoglobin value before treatment. However, hemoglobin value showed significant decreasing after 12 weeks of treatment with Regehep $(\mathrm{P}<0.001)$ when compared to hemoglobin value after 6 weeks of treatment (Table 6 ).

RBCs value showed non-significant differences after 6 and 12 weeks of treatment with Regehep $(\mathrm{P}>0.05)$ when compared to hemoglobin value before treatment. However, RBCs value showed non-significant differences after 12 weeks of treatment with Regehep $(\mathrm{P}>0.05)$ when compared to RBCs value after 6 weeks of treatment (Table 6).

Platelet count showed significant elevation after 6 and 12 weeks of treatment with Regehep $(\mathrm{P}<0.001)$ when compared to platelet count before treatment. However, platelet count showed significant elevation after 12 weeks of treatment with Regehep $(\mathrm{P}<0.001)$ when compared to platelet count after 6 weeks of treatment (Table 6).

ALT enzyme showed significant elevation after 6 and 12 weeks of treatment with Regehep $(\mathrm{P}<0.001)$ when compared to ALT enzyme value before treatment. However, ALT enzyme showed non-significant differences after 12 weeks of treatment with Regehep ( $\mathrm{P}>0.05)$ when compared to ALT enzyme after 6 weeks of treatment (Table 7).

AST enzyme showed significant decreasing after 6 and 12 weeks of treatment with Regehep $(\mathrm{P}<0.001)$ when compared to AST enzyme value before treatment. However, AST enzyme showed significant elevation after 12 weeks of treatment with Regehep $(\mathrm{P}<0.001)$ when compared to AST after 6 weeks of treatment (Table 7).

Albumin showed significant elevation after 12 weeks of treatment with Regehep $(\mathrm{P}<0.001)$ when compared to albumin value before and 6 weeks after treatment. However, it showed significant decreasing after 6 weeks of treatment with Regehep $(\mathrm{P}<00.01)$ when compared to albumin value before treatment (Table 7).

Total bilirubin showed significant decreasing after 6 and 12 weeks of treatment with Regehep $(\mathrm{P}<0.001 \& \mathrm{P}<0.01)$ when compared to total bilirubin value before treatment. While it showed significant elevation after 12 weeks of treatment with Regehep $(\mathrm{P}<0.001)$ when compared to total bilirubin value after 6 weeks of treatment (Table 7).

Direct bilirubin showed significant decreasing after 6 and 12 weeks of treatment with Regehep $(\mathrm{P}<0.001 \& \mathrm{P}<0.001)$ when compared to direct bilirubin value before treatment. While it showed significant elevation after 12 weeks of treatment with Regehep $(\mathrm{P}<0.01)$ when compared to direct bilirubin value after 6 weeks of treatment (Table 7).

Indirect bilirubin showed significant decreasing after 6 weeks of treatment 
with Regehep $(\mathrm{P}<0.01)$ when compared to direct bilirubin value before treatment. While it showed significant increasing after 12 weeks of treatment with Regehep $(\mathrm{P}<0.01)$ when compared to direct bilirubin value after 6 weeks of treatment (Table 7).

Creatinine showed significant decreasing after 12 weeks of treatment with Regehep $(\mathrm{P}<0.001 \& \mathrm{P}<0.01)$ when compared to creatinine value before and 6 weeks after treatment. However, it showed non-significant differences after 6 weeks of treatment with Regehep ( $P>0.05)$ when compared to creatinie value before treatment (Table 7).

Coagulation time showed significant decreasing 6 weeks of treatment with Regehep $(\mathrm{P}<0.01)$ when compared to time before treatment. However, it showed non-significant differences after 6 weeks of treatment with Regehep $(\mathrm{P}>$ 0.05 ) when compared to time before and after 12 weeks of treatment (Table 8).

Sample concentration showed significant elevation after 6 and 12 weeks of treatment with Regehep $(\mathrm{P}<0.001)$ when compared to concentration before treatment (Table 8).

I.N.R. showed significant decreasing after 6 and 12 weeks of treatment with Regehep $(\mathrm{P}<0.05 \& \mathrm{P}<0.001)$ when compared to concentration before treatment. However, it showed non-significant differences after 12 weeks of treatment with Regehep $(\mathrm{P}>0.05)$ when compared to value after 6 weeks of treatment (Table 8).

\section{Ultrasonography}

\section{Case 1}

Ultrasound image of the liver showed shrunken liver with severe periportal fibrosis, irregular boarders and coarse heterogeneous echogenicity before treatment (Figure 7). While after 3 weeks of treatment with Regehep, ultrasound image of liver showed average size liver with moderate periportal fibrosis, more regular boarder and less heterogeneous echogenicity when compared to ultrasound images before treatment (Figure 7). Moreover, after 6 weeks of treatment with Regehep ultrasound images of liver showed average size liver with mild to moderate periportal fibrosis, more regular boarders and less heterogeneous echogenicity when compared to ultrasound images before and 3 weeks after treatment (Figure 7).

\section{Case 2}

Ultrasound images of the liver showed shrunken liver with severe periportal fibrosis, irregular boarders and coarse heterogeneous echogenicity before treatment (Figure 8). While after 6 weeks of treatment with Regehep, ultrasound images of liver showed average size liver with mild to moderate periportal fibrosis, more regular boarder and less heterogeneous echogenicity when compared to ultrasound images before treatment (Figure 8). Moreover, after 12 weeks of treatment with Regehep ultrasound images of liver showed average size liver with no periportal fibrosis, regular boarders and less heterogeneous echogenicity 

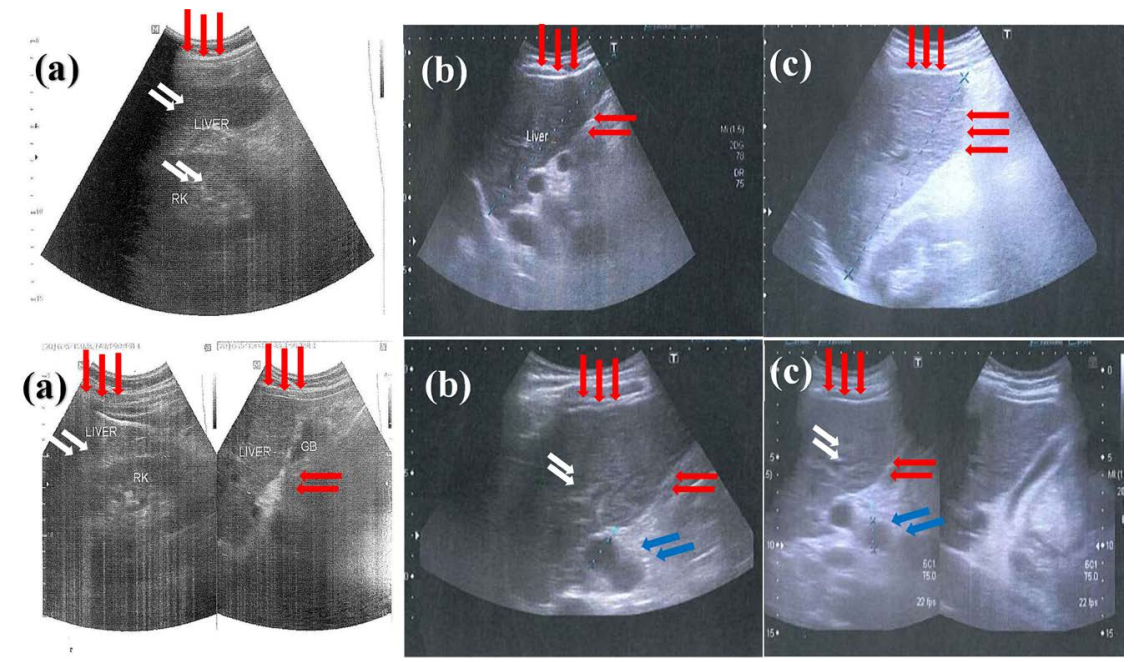

Figure 7. Ultrasound images of liver of case 1. (a) before administration of REGEHEP. (b) 3 weeks after administration of REGEHEP. (c) 6 weeks after administration of REGEHEP. Red arrows: Outlines and boarders of the liver. White arrows: Echogenicity of the liver and kidney. Blue arrows: Portal area.
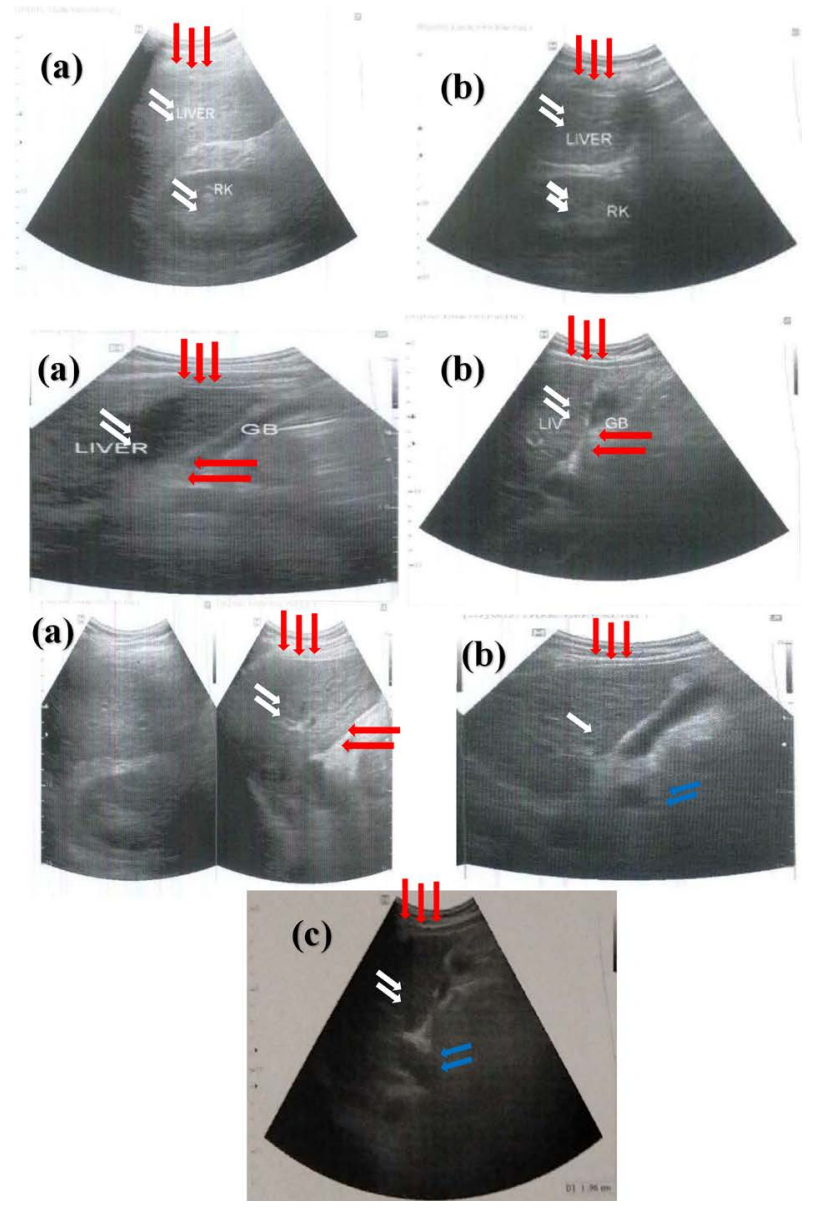

Figure 8. Ultrasound images of liver of case 2. (a) before administration of REGEHEP. (b) 6 weeks after administration of REGEHEP. (c) 12 weeks after administration of REGEHEP. Red arrows: Outlines and boarders of the liver. White arrows: Echogenicity of the liver and kidney. Blue arrows: Portal area. 
when compared to ultrasound images before and 6 weeks after treatment (Figure 8).

\section{Discussion}

In part A related to safety, there were no serious biochemical changes and adverse events after administration of single ascending doses of REHEHEP up to 25 folds of therapeutic dose. On the other hand, REGEHEP achieved the primary endpoint in case 1 as demanded by enhancing hematological values, liver profile and coagulation profile (Tables 6-8) in addition to restoring normal size of liver, more define echogenicity of liver parenchyma as well as more regular outline of liver (Figure 7). Moreover, secondary endpoint of case 2 was achieved by curing of periportal fibrosis (Figure 8), improvement of hematological biochemical values, and improvement of liver profile and finally enhancement of coagulation profile (Tables 6-8).

Subjects were asked how they fell 2.5 hours and 7.5 hours after administration of each single oral dose as the schedule of the trial. This takes advantages of differences between human and animal in preclinical studies i.e. they can be asked what is happening and how they fell. Side effects that subjects said they felt were reported (Table 5). They were presented as $(+)$ mild, $(++)$ moderate and $(+++)$ severe by each subject in each group. All tables of biochemical analysis related to part B are presented graphically as figures. Group 4 related to section of safety was withdrawn after first dose of 50 folds of therapeutic dose due to severity of side effects.

\section{Conclusion}

To-date, there is no effective drug for treatment for advanced (chronic) liver diseases. The only known way for patients suffering from advanced liver diseases is liver transplantation. Regehep proved a great efficacy in curing the periportal fibrosis, competent regeneration of damaged liver cells and restoring the size, shape, outlines as well as echogenicity of the liver safely without serious side effects. Regehep is an innovative molecule proved a wide range of safety index in healthy humans as well as patient with advanced liver fibrosis. Such a miracle was made true by Regehep. It opens a new era for treatment of chronic liver diseases and providing hope for millions suffering from liver cirrhosis. Finally, Rgehep is found to be a potential treatment for advanced liver fibrosis and proved its efficacy, tolerability and safety in both human and animal.

\section{Authors' Contribution}

The author was responsible for the interpretation of data, drafting and critically revising the manuscript for important intellectual content.

\section{Conflicts of Interest}

The author declares no conflicts of interest regarding the publication of this paper. 


\section{References}

[1] Brenner, D.A. (2013) Reversibility of Liver Fibrosis. Gastroenterology \& Hepatology, 9, 737-739.

[2] Karsdal, M.A., Krarup, H., Sand, J.M., Christensen, P.B., Gerstoft, J., Leeming, D.J., Weis, N., Schaffalitzky de Muckadell, O.B. and Krag, A. (2014) Review Article: The Efficacy of Biomarkers in Chronic Fibroproliferative Diseases-Early Diagnosis and Prognosis, with Liver Fibrosis as an Exemplar. Alimentary Pharmacology \& Therapeutics, 40, 233-249. https://doi.org/10.1111/apt.12820

[3] Mokdad, A.A., Lopez, A.D., Shahraz, S., Lozano, R., Mokdad, A.H., Stanaway, J., et al. (2014) Liver Cirrhosis Mortality in 187 Countries between 1980 and 2010: A Systematic Analysis. BMC Medicine, 12, 145. https://doi.org/10.1186/s12916-014-0145-y

[4] Pratt, D. and Kaplan, M. (1999) Evaluation of the Liver A: Laboratory Tests. In: Schiff, E., Sorrell, M. and Maddrey, W., Eds., Schiff s Diseases of the Liver, Eighth Edition, Lippincott Williams \& Wilkins, Philadelphia, 205.

[5] Schiff, E.R., Sorrell, M.F. and Maddrey, E.C. (2003) Schiff's Diseases of the Liver. 9th Edition, Lippincott, Williams \& Wilkins, Philadelphia.

[6] Tchelepi, H., Ralls, P.W., Radin, R. and Grant, E. (2002) Sonography of Diffuse Liver Disease. Journal of Ultrasound in Medicine, 21, 1023-1032. https://doi.org/10.7863/jum.2002.21.9.1023

[7] Wells, R.G., Kruglov, E. and Dranoff, J.A. (2004) Autocrine Release of TGF-Beta by Portal Fibroblasts Regulates Cell Growth. FEBS Letters, 559, 107-110. https://doi.org/10.1016/S0014-5793(04)00037-7

[8] Wu, D. and Cederbaum, A.I. (2009) Oxidative Stress and Alcoholic Liver Disease. Seminars in Liver Disease, 29, 141-154. https://doi.org/10.1055/s-0029-1214370

[9] Wynn, T.A. (2007) Common and Unique Mechanisms Regulate Fibrosis in Various Fibroproliferative Diseases. Journal of Clinical Investigation, 117, 524-529. https://doi.org/10.1172/JCI31487

[10] Davidson, D.G. and Eastham, W.N. (1966) Acute Liver Necrosis Following Overdose of Paracetamol. British Medical Journal, 2, 497-499. https://doi.org/10.1136/bmj.2.5512.497

[11] Germani, G., Hytiroglou, P., Fotiadu, A., Burroughs, A.K. and Dhillon, A.P. (2011) Assessment of Fibrosis and Cirrhosis in Liver Biopsies: An Update. Seminars in Liver Disease, 31, 82-90. https://doi.org/10.1055/s-0031-1272836

[12] Di Lelio, A., Cestari, C., Lomazzi, A. and Beretta, L. (1989) Cirrhosis: Diagnosis with Sonographic Study of the Liver Surface. Radiology, 172, 389-392. https://doi.org/10.1148/radiology.172.2.2526349

[13] Friedman, S.L. (2008) Mechanisms of Hepatic Fibrogenesis. Gastroenterology, 134, 1655-1669. https://doi.org/10.1053/j.gastro.2008.03.003

[14] Imbert-Bismut, F., Ratziu, V., Pieroni, L., Charlotte, F., Benhamou, Y. and Poynard, T. (2001) Biochemical Markers of Liver Fibrosis in Patients with Hepatitis C Virus Infection: A Prospective Study. The Lancet, 357, 1069-1075. https://doi.org/10.1016/S0140-6736(00)04258-6

[15] Brenner, D.A. (2009) Molecular Pathogenesis of Liver Fibrosis. Transactions of the American Clinical and Climatological Association, 120, 361-368.

[16] Bircher, J., Benhamou, J.P., McIntyre, N., Rizzetto, M. and Rodes, J. (1999) Oxford Textbook of Clinical Hepatology. 2nd Edition, Oxford University Press, Oxford. 